\title{
Relationship between oral hygiene and fungal growth in patients: users of an acrylic denture without signs of inflammatory process
}

This article was published in the following Dove Press journal:

Clinical Interventions in Aging

Izabela Gacon
Jolanta E Loster
Aneta Wieczorek

Department of Dental Prosthetics, Institute of Dentistry at Jagiellonian University, Kraków, Poland
Correspondence: Aneta Wieczorek Department of Dental Prosthetics, Institute of Dentistry at Jagiellonian University, Ul. Montelupich 4, 3I-I55 Kraków, Poland

Tel +48 I2 4245536

Email aneta.wieczorek@uj.edu.pl
Objectives: To answer to the following questions: is there any relationship between oral hygiene and the growth of yeast in patients without mucosal inflammation; and is there a need for mycological examination patients without mucosal inflammation?

Background: Patients with candidiasis may report varied symptoms, but such infections are most often asymptomatic. In addition to its high incidence in denture users $(60 \%-100 \%)$, there is a concern that Candida species from the oral cavity may colonize the upper gastrointestinal tract and lead to septicemia, which has a $40 \%-79 \%$ mortality rate and can require a prolonged hospital stay. It is thus important for all physicians to be aware of the risk factors, diagnosis, and treatment of oral candidiasis in older patients.

Methods: A retrospective study was carried out on a group of patients who had undergone mycological examination and assessment of the intensity of yeast growth, and oral hygiene. Results: Ninety-one denture wearers who lacked signs of clinical inflammation were included in the study. The growth of Candida albicans was as follows: 14 patients had up to 20 colonies; 19 patients had over 20 colonies. Ten percent of patients with good oral hygiene proved to have more than 20 yeast colonies. $5 \%$ of patients with bad oral hygiene had more than 20 colonies.

Conclusions: There was no relationship found between hygiene and the growth rate of fungal microorganisms. In patients without clinical symptoms of stomatitis, mycological examination should be considered.

Keywords: removable dentures, stomatitis, hygiene, Candida albicans

\section{Introduction}

Oral fungal infection is a common disease in wearers of dentures. ${ }^{1-5}$ The long-term use of removable acrylic dentures creates the ideal environment for the growth of yeasts, resulting in the development of denture-related stomatitis (DRS). ${ }^{6,7}$

DRS refers to an inflammatory process of the mucosa underlying removable partial or full dentures, and involves inflammation and erythema of the oral mucosal areas covered by the denture. ${ }^{8}$ DRS presents different degrees of severity, ranging from petechiae to generalized inflammation with papillary hyperplasia. Diagnosis is usually made after the observation of inflammation on the palatal mucosa. ${ }^{4}$ The first classification of denture stomatitis stems from the work of Newton in 1962 and describes three types of stomatitis, according to the level of inflammation:

1. Pink spots on healthy mucosa located near the salivary duct ends. 
2. Erythema covers the whole mucosa under the dentures. The mucosa itself is quite sensitive and bleeds easily.

3. Papillary hyperplasia of the palate

The etiology of denture stomatitis is multifactorial, with factors including trauma caused by ill-fitting dentures, increased age of the patient and of the dentures, lack of prosthesis hygiene, and a favorable environment for the proliferation for Candida albicans in particular., ${ }^{4,5,8,9}$

Patients with candidiasis may report varied symptoms - such as painful sensations, local discomfort, difficulty swallowing, a burning sensation in the oral cavity, or an alteration in taste - but such infections are most often asymptomatic. ${ }^{10}$ In addition to its high incidence in denture users $(60-100 \%)$, there is a concern that Candida species from the oral cavity may colonize the upper gastrointestinal tract (especially in immunosuppressed patients) and lead to septicemia, which has a $40-79 \%$ mortality rate and can require a prolonged hospital stay., ${ }^{4,11}$ It is thus important for all physicians to be aware of the risk factors, diagnosis, and treatment of oral candidiasis in older patients.

Candida albicans is commensal in the oral cavity of $45-65 \%$ of healthy individuals, but in denture wearers, the prevalence of Candida increases to $60-100 \%,{ }^{1,2,3,4,5}$ which increases the risk of infection. In cases where no symptoms of inflammatory state are evident, it is interesting to ask whether a yeast growth susceptible to pharmaceutical treatment is in fact present. Thus, for the purpose of this article, a fourth "zero" classification is employed to accommodate patients without inflammation of the oral mucosa. The members of this group of denture wearers have healthy mucosa and no clinical signs of inflammations. In some of these cases, mycological examination revealed an intense fungal growth. This shows that we should carefully consider the results of clinical and mycological examinations in this group. From 2007 findings by Loster et al, which show that Candidiasis of oesophageal mucosa is often connected with mycosis in complete denture users, in our Department we started to follow the mycological examination, who wear removable denture and would like to have the new one. For our study, we chose randomly selected one year, from the period in which the mycological examination of users of removable denture was in our Department obligatory. Our research thus focuses on patients without mucosal inflammation.

\section{The aim of the study}

The purpose of this article is to provide answers to the following questions:

1. Is there any relationship between oral hygiene and the growth of yeast in patients without mucosal inflammation?

2. Is there a need for mycological examination among denture-wearing patients without mucosal inflammation?

\section{Materials and methods}

The research was done with the accordance of the Bioethics Committee of Jagiellonian University KBET/103/B/2004 and conformed to the criteria of The Helsinki Declaration And the International Council on Harmonisation good clinical practical guidelines. All participants signed written consent to participate in the study.

A study was carried out on a group of patients seeking prosthetic treatment at the Prosthetic Department of the University Dental Clinic from March 2012 to February 2013. All data were collected in the electronic medical journals of the patients using the KS-SOMED software system (Kamsoft, Katowice, Poland). The study's inclusion criteria were patients using upper full or partial denture who received a clinical mucosa examination result of 0 on our modified Newton classification (as described previously). The exclusion criteria of our study were patients with postoperative or framework denture, xerostomia, medications, smoking, immuno-suppression, hormonal disorders, or with lack of necessary data.

All patients were clinically examined by a specialist in prosthetic dentistry. The mycological examination was performed in line with a uniform protocol, involving swabbing the palate between second and third palatal folds, immediately after removal of the upper denture. The intensity of yeast growth was classified by quantitative assessment, as follows:

Level 0: lack of fungal growth, up to 10 colonies;

Level 1: scarce growth, 11-20 colonies;

Level 2: intermediate growth, 21-50 colonies;

Level 3: intense growth, 51-100 colonies;

Level 4: abundant growth, more than 100 colonies.

After mycological examination, antifungal susceptibility was determined for patients in classes 2, 3, and 4 using a fungi test (Bio-Rad, Marnes-la-Coquette, France) and by the 
disk-diffusion method with Nystatin 100 units (Emapol, Gdańsk, Poland).

An assessment of oral hygiene was carried out using our own classification:

0: no plaque, very good hygiene;

1: good hygiene;

2: satisfactory hygiene;

3: bad hygiene; and

4: bad breath (fetor ex ore).

Data on general health status - including systemic diseases such as diabetes, high blood pressure, and heart disease - were examined in the context of the fungal growth.

\section{Statistical analysis}

A number of statistical analyses were carried out using program R, v. 3.5.1., R Core Team (2017). R: A language and environment for statistical computing. R Foundation for Statistical Computing, Vienna, Austria. URL https:/www.Rproject.org/. A value of $P<0.05$ was considered significant.

\section{Results}

Of the 289 patients who reported for treatment in the study period, 91 full or partial denture wearers lacked signs of clinical inflammation on the palatal mucosa (level 0 in our modified Newton scale). This group constituted our study population, consisting of 29 males (31\%) and 62 females $(69 \%)$. The age range was $22-81$ years in males and 50-88 years in females, with an average age of 66 years for all patients. Sixty-two patients, a majority (69\%), had complete dentures, while 29 had partial dentures (31\%). The microbiological examination dealt with six species.

Fifty-three percent of patients in the group with Newton classification 0 proved to have Candida spp. growth.

Candida albicans was the predominant yeast in 33 patients (36\% of 91 patients). The growth of Candida albicans was diverse: 14 patients $(42 \%$ of the 33 in whom C. albicans predominated, or $15 \%$ of all 91 patients) had up to 20 colonies, 13 patients ( $39 \%$ of 33 or $14 \%$ of 91 ) had up to 50 colonies, and six people ( $18 \%$ of 33 or $7 \%$ of 91 ) had up to 100 colonies of Candida albicans (Table 1).

The growth of up to 20 colonies of yeast (levels 0 and 1) does not require antifungal treatment. In the study group, yeast growth above level 1 was observed in 31 patients $(34 \%$; Table 1). All these patients require antifungal treatment, despite having no visible signs of DRS.

In our study, 14 patients had more than one species of Candida in the mycological test. The second most common yeast was Candida glabrata coexisting with Candida albicans. Table 2 shows the coexistence of Candida albicans with other Candida species in our study.

Hygiene was examined in 91 patients, consisting of 62 females (68\%) and 29 males (32\%). 62 patients (68\%) had complete dentures while $29(32 \%)$ used partial dentures (Table 3). A majority of patients (55 people; $60 \%$ of the whole group) had satisfactory hygiene: this was $62 \%$ of females and $59 \%$ of males. Fifteen percent (14 people) had bad hygiene, constituting $21 \%$ of males and $13 \%$ of females.

The relationship between oral hygiene and yeast growth was then determined: Table 4 shows the hygiene status of patients with growth of Candida species.

In the 22 patients with good hygiene, Candida species were detected in $59 \%$ of patients. There were no patients with hygiene classes 0 or 4 .

Ten percent of patients with good oral hygiene proved to have more than 20 yeast colonies in microbiological examination (9 of 91 patients). Five percent of patients with bad oral hygiene had more than 20 colonies (5 of 91 patients; Table 5)

\section{Discussion}

Candida yeast colonies were found in the oral cavity of 60$100 \%$ of the denture-wearing people examined here. ${ }^{1,2,3,4,5,12}$ In our study, $53 \%$ of denture users who did not show signs of inflammation had Candida infections.

Many authors have reported that Candida albicans is the most common species in denture users, ${ }^{1,2,3,4,13,14,15,16}$ making up $70 \%$ of all isolates. ${ }^{17}$ This is also true for patients who show no sign of inflammation, and this was validated in our study, where Candida albicans was detected in $67 \%$ of all of the isolates of Candida spp. As many authors have reported, candidiasis occurs regardless of clinical signs. ${ }^{1}$ Some of these patients were unaware of their denture-related stomatitis because of the lack of inflammatory signs. ${ }^{1,4}$ In $34 \%$ of patients without inflammation, we observed high levels of fungal growth requiring antimycotical treatment.

The occurrence of more than one Candida species colony has been reported by many authors. $4,6,7,17$

The study of Coco et $\mathrm{al}^{6}$ demonstrated that mixed Candida albicans and Candida glabrata biofilms may play an important role in the pathogenesis of severe inflammation in denture wearers. ${ }^{7}$

In our study, $21 \%$ of people with fungal growth had a coinfection of Candida albicans with Candida glabrata.

Many studies have also shown that hygiene denture practices are essential, because the porous material of the 
Table I The yeast species isolated from the palatal mucosa of patients with no signs of inflammation, according to growth

\begin{tabular}{|c|c|c|c|c|c|c|}
\hline & Level 0 & Level I & Level 2 & Level 3 & Level 4 & Total \\
\hline Candida albicans & & $42 \%(14)$ & $39 \%(13)$ & $18 \%(6)$ & & $33(36 \%)$ \\
\hline Candida dubliniensis & & $100 \%(1)$ & & & & I (I\%) \\
\hline Candida famata & & & $50 \%(I)$ & $50 \%(1)$ & & $2(2 \%)$ \\
\hline Candida glabrata & & $14 \%(1)$ & $71 \%(5)$ & & $14 \%(1)$ & 7 (8\%) \\
\hline Candida tropicalis & & & 0 & $33 \%(1)$ & $67 \%(2)$ & $3(3 \%)$ \\
\hline Candida kefyr + NMF-S & & $50 \%(I)$ & $50 \%(I)$ & & & $2(2 \%)$ \\
\hline No growth & $47 \%(43)$ & & & & & $43(47 \%)$ \\
\hline Total & $47 \%(43)$ & $19 \%(17)$ & $22 \%(20)$ & $9 \%(8)$ & $3 \%(3)$ & $91(100 \%)$ \\
\hline
\end{tabular}

Notes: Level 0: no fungal growth: up to 10 colonies; Level I: scarce growth: II-20 colonies; Level 2: intermediate growth: 2I-50 colonies; Level 3: intense growth of 5I100 colonies; Level 4: abundant growth: more than 100 colonies. Exact Fisher test $p=0.01$.

Abbreviation: NMF-S, nystatin, miconazole, fluconazole sensitivity.

Table 2 Coexistence of Candida albicans with other Candida species

\begin{tabular}{|l|l|}
\hline Growth & $\%$ (n) \\
\hline Growth I (growth in 48=100\% of patients) & \\
C. albicans & $69 \%(33)$ \\
C. glabrata & $15 \%(7)$ \\
C. tropicalis & $6 \%(3)$ \\
C. kefyr & $4 \%(2)$ \\
C. famata & $4 \%(2)$ \\
C. dubliniensis & $2 \%(1)$ \\
\hline Growth 2 in I4 patients (from 48 who showed growth) & \\
C. glabrata & $21 \%(10)$ \\
C. tropicalis & $4 \%(2)$ \\
C. crusei & $2 \%(1)$ \\
Saccharomyces cerevisiae & $2 \%(I)$ \\
\hline
\end{tabular}

Table 3 Relationships between gender and hygiene

\begin{tabular}{|l|l|l|l|}
\hline Hygiene & Females & Males & Total \\
\hline 0 no plaque & 0 & 0 & 0 \\
I good & $16(26 \%)$ & $6(21 \%)$ & $22(24 \%)$ \\
2 satisfactory & $38(62 \%)$ & $17(59 \%)$ & $55(60 \%)$ \\
3 bad & $8(13 \%)$ & $6(21 \%)$ & $14(15 \%)$ \\
4 bad breath & 0 & 0 & 0 \\
Total & $62(68 \%)$ & $29(32 \%)$ & $91(100 \%)$ \\
\hline
\end{tabular}

Note: Exact Fisher test $p=0.659$.

surface biofilm can serve as a reservoir of fungal microorganisms and contribute to reinfection. ${ }^{18,19}$

Numerous studies have demonstrated a clear association between poor denture hygiene and increased risk of (and prevalence of) denture stomatitis. ${ }^{20,21}$

Budtz-Jorgensen and Bertram reported that poor denture hygiene was associated with increased denture and oral mucosal colonization with Candida, as well as with increased severity of inflammation stomatitis in patients who used full dentures. ${ }^{19}$

Both the accumulation of plaque on the denture and poor oral hygiene contribute to the virulence of Candida, contributing to the clinical image of Candida-associated denture stomatitis. ${ }^{10,19}$

In our study, only five people ( $16 \%$ of patients who required antifungal treatment) lacking inflammation signs had bad hygiene. Most of the patients (26, being $84 \%$ of those who needed antifungal treatment) had good or satisfactory hygiene. We detected no connection between hygiene and the intensity of fungal growth in the patients in Newton class 0 .

The findings of Loster et al, as well as those of Nikawa, have shown that oral mycosis in denture users can affect the mycosis of esophageal mucosa. ${ }^{1,22}$ Correct diagnosis and treatment of oral candidiasis in the proper time, especially in elderly people, can prevent progress of the infection and dangerous complications. ${ }^{15}$

Helicobacter pylori, if present inside Candida yeast, could play an important role in the bacterial reinfection of the stomach and could be a reservoir of Helicobacter pylori for transmission to new locations. Such a finding might clarify the persistence of Helicobacter pylori in the gastrointestinal tract. ${ }^{1}$

In contrast to other studies, such as those of Dar-Odeh and Skupien, ${ }^{13,14}$ we found no significant relationship between oral hygiene and the growth of Candida species ( $p=0.332)$; however, those studies were carried out in patients with inflammation of palatal mucosa, In our study, $59 \%$ of patients with good oral hygiene were shown to have Candida species by the microbiological examination. No patients in our study group fell into hygiene class 0 (no plaque) or 4 (bad breath). Our results may differ due to our smaller number of participants, or due to other issues associated with their age and general health. 

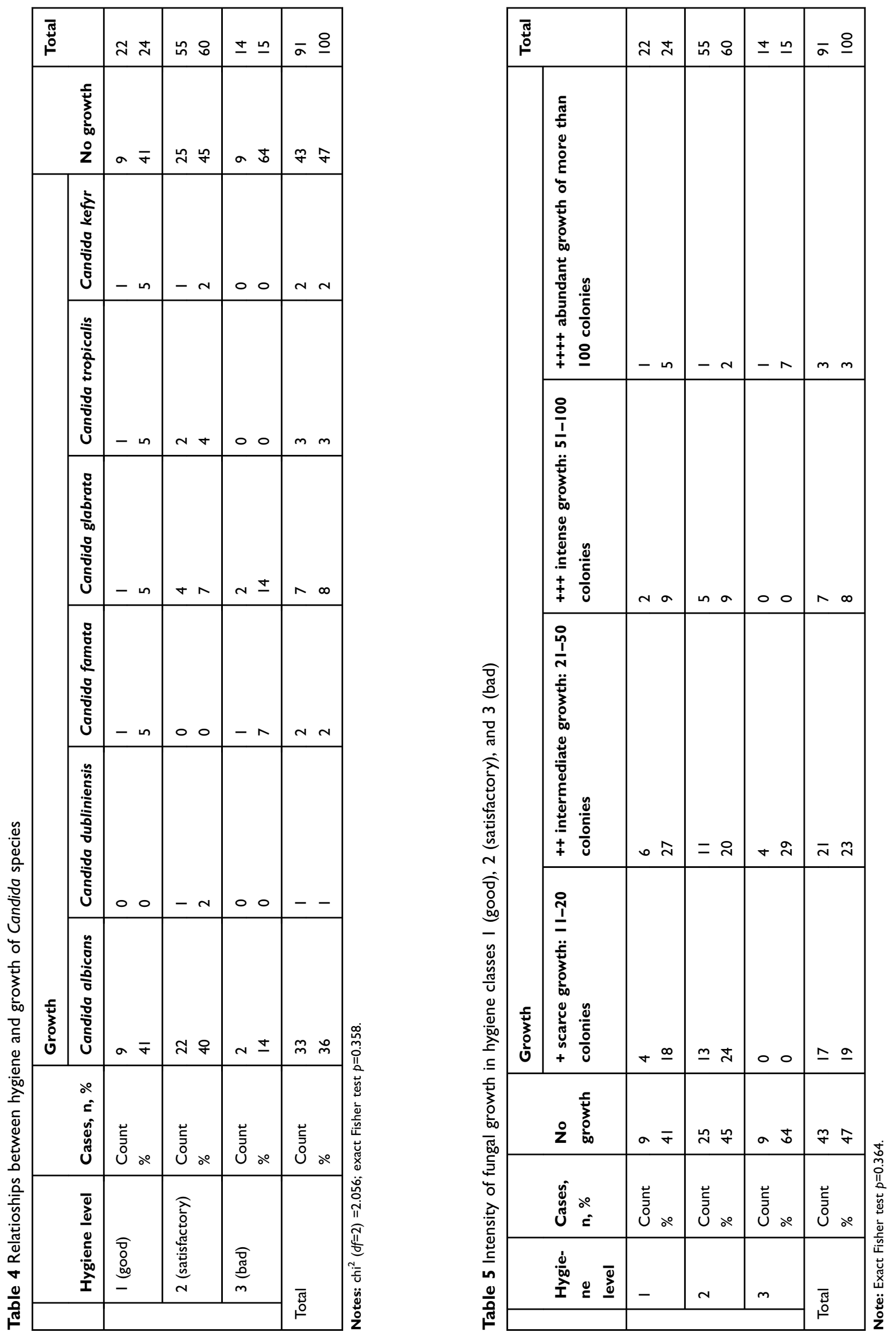


\section{Conclusions}

There was no relationship found between hygiene and the growth rate of fungal microorganisms in patients lacking signs of inflammation.

In patients without clinical symptoms of stomatitis, mycological examination should be considered. This study is based on a small sample size so further research is required to evaluate the association of oral Candidal carriage in denture wears and risk of Candidal infection.

\section{Disclosure}

The authors declare no potential conflicts of interest with respect to the authorship and publication of this article.

\section{References}

1. Loster BW, Loster J, Wieczorek A, Ryniewicz W. Mycological analysis of the oral cavity of patients using acrylic removable dentures. Gastroenterol Res Pract. 2012;Article ID 951572, 9. doi:10.1155/2012/ 951572

2. Loster JE, Wieczorek A. Loster BW: correlation between age and gender in Candida species infections of complete denture wearers: a retrospective analysis. Clin Interv Aging. 2016;11:1707-1714. doi:10.2147/CIA.S116658

3. Zomorodian K, Haghighi NN, Rajaee N, et al. Assessment of Candida species colonization and denture-related stomatitis in complete denture wearers. Med Mycol. 2011;49:208-211. doi:10.3109/ 13693786.2010.507605

4. Akpan A, Morgan R. Oral candidiasis. Postgrad Med J. 2002;78:455459. doi:10.1136/pmj.78.922.455

5. Abaci O, Haliki-Uztan A. Investigation of the susceptibility of Candida species isolated from denture wearers to different antifungal antibiotics. Afr J Microbiol Res. 2011;5:1398-1403. doi:10.5897/AJMR10.693

6. Silva S, Henriques C, Hayes A, Oliveira R, Azeredo J, Williams W. Candida glabrata and Candida albicans co-infection of an in vitro oral epithelium. J Oral Pathol Med. 2010;40:421-427. doi:10.1111/j.16000714.2010.00981.x

7. Coco BJ, Bagg J, Cross LJ, Jose A, Cross J, Ramage G. Mixed Candida albicans and Candida glabrata populations associated with the pathogenesis of denture stomatitis. Oral Microbiol Immunol. 2008;23:377-383. doi:10.1111/j.1399-302X.2007.00420.x
8. Wilson J. The aetiology, diagnosis and management of denture stomatitis. Br Dent J. 1998;185:380-384. doi:10.1038/sj.bdj.4809821

9. Webb BC, Thomas CJ, Willcox MDP, et al. Candida-associated denture stomatitis: aetiology and management: a review: part I: factors influencing distribution of Candida species in the oral cavity. Aust Dent J. 1998;43:45-50.

10. Hoshi N, Mori H, Taguchi H, et al. Management of oral candidiasis in denture wearers. J Prosthodont Res. 2011;55:48-52. doi:10.1016/j. jpor.2011.01.004

11. Fraser VJ, Jones M, Dunkel J, et al. Candidemia in a tertiary care hospital: epidemiology, risk factors, and predictors of mortality. Clin Infect Dis. 1992;15:414 421. doi:10.1093/clind/15.3.414

12. Daniluk T, Tokajuk G, Stokowska W, et al. Occurrence of rate of oral Candida albicans in denture wearer patients. Adv Med Sci. 2006;51:77-80

13. Dar-Odeh NS, Shehabi AA. Oral candidosis in patients with removable dentures. Mycoses. 2003;46:187-191.

14. Skupien JA, Valentini F, Boscato N, Pereire-Cenci T. Prevention and treatment of Candida colonization on denture liners: a systematic review. J Prost Dent. 2013;5:356-362. doi:10.1016/j.prosdent.2013.07.003

15. Petkowicz B, Skiba-Tatarska M, Wysokińska-Miszczuk J. Kandydoza jamy ustnej. Gerontologia Polska. 2006;4:160-164.

16. Cubera K. Stomatopatie protetyczne: definicja, etiologia, klasyfikacja oraz leczenia. Przeglad Lekarski. 2013;70:947-949.

17. D'aistan S, Aktas AE, Caglayan F, Ayyildiz A, Bilge M. Differential diagnosis of denture-induced stomatitis, Candida, and their variations in patients using complete denture: a clinical and mycological study. Mycoses. 2009;52:266-271. doi:10.1111/j.1439-0507.2008.01592.x

18. Hoshing C, Dixit S, Mootha A, Diwan N. Role of Candida albicans in denture stomatitis. J Indian Acad Oral Med Radiol. 2011;23:617619. doi:10.5005/jp-journals-10011-1234

19. Dantas APFM, Consani RLX, Sardi JCO, Mesquita MF, Silva MCVS. Sinhoreti MAC: biofilm formation in denture base acrylic resins and disinfection method using microwave. $J$ Res Pract Dent. 2014;Article ID 112424. doi:10.5171/2014.112424

20. Budtz-Jorgensen E, Bertram U. Denture stomatitis I. The etiology in relation to trauma and infection. Acta Odontol Scand. 1970;28:71-92. doi:10.3109/00016357009033133

21. Kulak-Ozkan Y, Kazazoglu E, Arikan A. Oral hygiene habits, denture cleanliness, presence of yeasts, and stomatitis in elderly people. $J$ Oral Rehabil. 2002;29:300-304. doi:10.1046/j.1365-2842.2002.00816.x

22. Nikawa H, Hamada T, Yamamoto T. Denture plaque - past and recent concerns. J Dent. 1998;26:pp. 299-304. doi:10.1016/S0300$5712(97) 00026-2$
Clinical Interventions in Aging

\section{Publish your work in this journal}

Clinical Interventions in Aging is an international, peer-reviewed journal focusing on evidence-based reports on the value or lack thereof of treatments intended to prevent or delay the onset of maladaptive correlates of aging in human beings. This journal is indexed on PubMed Central, MedLine, CAS, Scopus and the Elsevier
Bibliographic databases. The manuscript management system is completely online and includes a very quick and fair peer-review system, which is all easy to use. Visit http://www.dovepress.com testimonials.php to read real quotes from published authors. 